\title{
Food Security and Climate Change in Sub-Saharan Africa
}

\section{Chase McGowan}

Carleton University

\begin{abstract}
Climate change is predicted to have a detrimental impact on food security throughout the world, but the poorest regions are likely to be the most affected. The Food and Agriculture Organization identifies four aspects of food security: availability, access, stability and utilization. This literature review examines the predicted impacts of climate change on food security in Sub-Saharan Africa. First, an analysis of the scientific literature was undertaken to investigate the potential impact of climate change on each of these four aspects. Second, policies relating to food security and climate change of key UN bodies, international non-profit organizations, and national governments in Sub-Saharan Africa were examined. Overall, there is extensive evidence that climate change will negatively impact each of the four aspects of food security in Sub-Saharan Africa. Until now, international organizations and national governments have failed to adopt comprehensive policies to adapt to climate change. To be effective, efforts to address the problem should combine social and development aspects.
\end{abstract}

\section{Introduction}

Food security exists when individuals have access to safe and nutritious food in the appropriate quantity to enable a healthy lifestyle (FAO 2015). The Food and Agriculture Organization describes food security and nutrition as consisting of four key aspects: availability, access, stability and utilization. Availability refers to quantity, quality and diversity of nutrition. Accessibility depends on incomes, prices, and markets. Even if food is available it may not be accessible if it is too costly or transportation is poor. Stability is the extent to which individuals are subject to fluctuations in access to food. It is impacted by weather conditions, political and economic turmoil and inconsistent food prices. Lastly, utilization links directly with the biological dimension of food. Utilization is the body's ability to digest and use the nutrients present in food, and it is dependent on factors such as eating habits, health status and the method of food preparation.

Food security and agriculture are intricately linked. Agriculture is considered to be one of the activities most vulnerable to climate change because it is entirely dependent on weather and climate variables (Kotir 2011). There is broad consensus that Sub-Saharan Africa (SSA) is the region least resilient to climate change (Challinor, et al. 2007, Thornton, et al. 2011, Kotir 2011). According to the Fifth Assessment Report of the Intergovernmental Panel on Climate Change (IPCC), climate change will impact other drivers to increase the vulnerability of agriculture in Africa (Niang, et al. 2014). This has grim implications in a region already characterized by a lack of food security.

Until 2050, climate change will mainly exacerbate underlying problems (IPCC 2014). Already poor nutrition will become worse. Food security will be undermined by problems associated with working outdoors in high heat and high humidity. Water and food availability will be severely damaged, particularly in rural areas. Population displacements are expected to increase in SSA due to extreme weather events, further destabilizing food security.

Despite increasingly difficult conditions, broad international support to improve food security in SSA has been weak. Most notably, the FAO has produced rather baffling literature on the outlook for food security in SSA in the coming decades. The subtitle of the FAO Regional Overview of Food Insecurity for Africa 
(2015) is "African Food Security Prospects Brighter than Ever". The report highlights improvements in nutrition in SSA over the last few decades, such as a $10 \%$ reduction in the number of undernourished individuals. The FAO goes on to recognize climate change as a challenge for African agriculture in the near future, but it sees climate change as secondary to inequality, poverty, high population growth and the impacts of globalization.

However, other reputable sources such as the IPCC, the World Food Program (WFP) and the UN High Level Panel on the Post-2015 Development Agenda all describe climate change as a significant threat to food security and nutrition in SSA. In fact, the High Level Panel states: "Without tackling climate change, we will not succeed in eradicating extreme poverty" (UN 2013, 55). Thus, the question of the effect of climate change on food security in SSA is worthy of consideration because there appears to be contradictions in the literature.

The purpose of this literature review is to examine the question: how is climate change predicted to impact food security in Sub-Saharan Africa? The effect of climate change on the four aspects of food security will be discussed first and I will identify some gaps in the literature. Then, the policy responses of international organizations and African governments will be examined and suggestions for policy improvements will be made. I argue that, contrary to suggestions of the FAO, food security in SSA will be severely negatively impacted by climate change, which must be recognized as a preeminent risk. The aspect of food security most powerfully impacted will be availability. I recommend adaptations to climate change be mainstreamed into development goals and national planning and for no-regret options to be pursued.

\section{Methodology}

The literature search was divided into two parts. First, literature was found that described the impact of climate change on food security. Articles which specifically looked at food availability, stability, access and utilization were given priority. As the most authoritative and comprehensive synthesis of research on the potential impacts of climate change, the Fifth Assessment Report of the Intergovernmental Panel on Climate Change was foundational to my research. As well, articles which critically examined the gaps in food security and climate change research were identified and included.

Second, I searched for policy literature from a wide variety of sources to create a holistic overview of national and international policies. I attempted to include articles describing the policies of international organizations (e.g., the FAO), sub-Saharan countries (e.g., Niger), and non-governmental organizations (e.g., the Bill and Melinda Gates Foundation). I searched within the journal Climate Policy as one of the most relevant, peer-reviewed sources of literature. Since many organizations and countries are beginning to develop policies to improve food security in the face of climate change, my analysis should be taken as a survey of relevant policies and areas for improvement, rather than as a comprehensive listing.

\section{Stability and Access}

Stability and access are considered together here because they are related and largely dependent on similar factors. Individuals who earn/produce just enough to survive and have few reserves are subject to food instability. These individuals are at risk of losing access to food because they are not insulated against price shocks, income shocks, or weather changes. Climate variability is recognized as a significant source of unstable access to food because it harms the ability of labourers to earn wages from farm activities and the ability of subsistence farmers to grow enough to survive (Schmidhuber and Tubiello 2007). 
Rain is the most important driver of agricultural yields in Africa (Kotir 2011) and more than 70\% of agriculture in SSA is rain fed (Porter, et al. 2014). A key theme in the literature is that climate change will adversely impact the stability of food supplies by increasing the frequency and intensity of extreme events such as droughts, storms and heat waves (Challinor, et al. 2007). Extreme events will hamper the ability of food systems to control and establish food reserves and provide consistent prices for consumers (Niang, et al. 2014). Policies to improve irrigation to stabilize water supplies are worthy of consideration (Nkonya, et al. 2011).

Relative to the rest of the world, SSA will be disproportionately affected by dry conditions. Although changes in climate will not be uniform across all of Africa, models predict that on average the continent will get hotter and drier. Average temperatures in SSA may increase by $2-4.5^{\circ} \mathrm{C}$ or more in the coming decades (Kotir 2011). Several different models predict a reduction in arable land and crop productivity in SSA due to warming. This stands in contrast to some other areas of the world, such as Central Asia and the Russian Federation, which may experience an expansion in the area of arable land (Schmidhuber and Tubiello 2007). In SSA, many regions could be forced out of production entirely. In some countries, growing seasons may become $20 \%$ shorter, reducing incomes for farmers and farm labourers. SSA could experience the largest decline in agricultural incomes in the world. As a result of ocean acidification and other factors, fisheries in coastal countries might lose about $50 \%$ of jobs (Niang, et al. 2014).

Due to a combination of all of these factors, situations of temporary food insecurity in SSA will increase in frequency (Thornton, et al. 2011). Smaller global food reserves and higher demand for agricultural commodities will erode the ability of international organizations to provide food aid to SSA in the event of a disaster. Furthermore, climate risks during any given year are not mutually exclusive, meaning many countries all over the world could face crop failures simultaneously. One policy implication is that national governments may need to become more self-sufficient in building food reserves during productive years in order to prepare for years when crops fail.

In Mozambique, Kenya, and Ethiopia 50\% of smallholder farmers are net purchasers of cereal staples (Niang, et al. 2014). As the ability of local farmers to produce food falters due to climate change, farmers and those who rely on agricultural incomes will be forced to buy more food from the market. The supply of food available at a reasonable price will decrease. Although freer global trade could theoretically enhance sub-Saharan access to food commodities, this access will be hindered by high global prices resulting from growing populations and climate instability (Kotir 2011). Some estimates suggest that there will be 8 to 10.5 billion people in the world by 2050, further crimping food supplies (Thornton, et al. 2011). Overall, the ability of all Africans to achieve a stable and nutritious diet at a reasonable price will be adversely affected by climate change.

\section{Availability}

Broad consensus exists that climate change will reduce net agricultural yields in SSA, causing food availability to decrease (Thornton, et al. 2011, St. Louis and Hess 2008, Watts, et al. 2015). Indeed, this literature review confirms that the majority of evidence suggests food availability will be the aspect of food security most strongly affected by climate change. One factor involved will be direct loss of cropland. Overall, SSA will lose about 35\% of cropland (Thornton, et al. 2011), the greatest reduction in the world (Schmidhuber and Tubiello 2007). Moreover, the frequency of failed seasons will increase (Niang, et al. 2014). 
A key theme in the literature is that both direct and indirect effects of climate change will be important (Niang, et al. 2014). Direct effects include timing and amount of rainfall, flooding, drought and high temperatures. Indirect effects may stem, for example, from soil erosion during storms or the spread of crop pests and disease. While national governments and international organizations can have little influence over the direct effects of climate change and their impact on food availability, the pursuit of noregret policy options may alleviate some indirect effects. For instance, planting shelterbelts (rows of trees surrounding farms) can help to reduce soil erosion due to storm winds. This is a no-regret option because, regardless of the eventual potency of climate change, shelterbelts can help to reduce soil erosion due to wind. There are many policies available today which can provide real time benefits to farmers and consumers, while helping to prepare for the potential impacts of climate change in the future.

Yields of major cereal crops in Africa will decrease due to increased temperatures and changes in rainfall, though there will be variability between regions (Niang, et al. 2014). For example, maize production in East Africa at high elevations may benefit from climate change, but maize farming in southern Africa will be particularly vulnerable. South Africa and Zimbabwe are predicted to lose more than $30 \%$ of their maize yields. Under some climate change scenarios, wheat production is projected to fall by $35 \%$ by 2050 . Highvalue perennial crops such as coffee, tea, and cocoa will also be negatively impacted, affecting export earnings.

Agricultural production will be indirectly affected by climate change if petroleum or artificial fertilizers become scarce or more expensive due to carbon taxes or cap-and-trade systems (St. Louis and Hess 2008). Biofuel production may also increase commodity prices and productive cropland may be diverted for this purpose. Climate change may have numerous other indirect impacts on availability such as increased food spoilage (Niang, et al. 2014) and potential conflicts over food or water sources (Watts, et al. 2015). An implication of these varied direct and indirect effects is that agricultural policies to improve food availability may be difficult to formulate owing to the complexity of factors involved.

Crops and livestock are both expected to face new risks due to the spread of infectious disease (Thornton, et al. 2011). Furthermore, livestock systems in Africa may be especially impaired by interactions between climate change and other stressors such as fragmented grazing areas, rangeland degradation and insecure access to land and markets (Niang, et al. 2014). Lack of sufficient water resources is already considered a constraint on economic growth in SSA and livestock productivity and mortality will be harmed by growing water scarcity due to climate change (Niang, et al. 2014). Policies which aim to conserve water and to preserve pastureland from degradation should be closely examined by decision makers.

Drought, extreme weather and sea-level rise will cause entire populations to relocate, which will also impact food availability (Thornton, et al. 2011). Low income developing countries will be highly exposed to climate change and population displacements are expected to increase due to extreme weather events, further destabilizing food security (IPCC 2014). This holds policy and security implications for countries that are less affected by climate change, as these countries may be destinations for populations displaced by hunger.

\section{Utilization}

Food utilization may be negatively impacted by climate change, but only in subtle ways. Poor food and potable water availability will reduce nutrition status and increase the probability of infection (St. Louis and Hess 2008). Infection would further reduce the ability of individuals to fully digest food. Vicious cycles of hunger, infectious disease, falling labour productivity, poverty and mortality could become common 
(Schmidhuber and Tubiello 2007). Infectious diseases may spread as populations are displaced due to famine. As well, high atmospheric carbon dioxide $\left(\mathrm{CO}_{2}\right)$ can reduce the nutritional value of some crops, such as cereal grains and cassava (Porter, et al. 2014). For instance, evidence shows that protein levels are reduced by $10-14 \%$ in wheat, barley, potatoes and rice grown at elevated $\mathrm{CO}_{2}$ levels. Mineral concentrations may also be adversely affected (Porter, et al. 2014).

\section{Nutrition and Research Gaps}

The literature suggests that each of the four aspects of food security will be negatively impacted by climate change. Much can be done to improve access to food and the stability of food systems through improvements to international markets, transportation infrastructure and the establishment of emergency food supplies for famines. However, food availability is a more difficult problem to solve because it is directly dependent on agricultural output, which is closely tied to the climate. In other words, there are fewer adaptation mechanisms available to improve food availability. Although these aspects were examined separately above, it should be recognized that they are linked to and feedback on one another. For instance, reduced food availability due to falling production in one country in SSA will impact access to food in other countries by reducing the potential for trade.

It should be noted that changes in population levels in SSA will be an important factor in determining food availability. The IPCC incorporates population growth into its Special Report on Emissions Scenarios with the A2 model assuming the highest projected population growth of the four scenarios (A1, A2, B1, B2) (Schmidhuber and Tubiello 2007). With the highest population growth, A2 will also have the highest demand for food.

There is broad consensus that nutrition will be adversely affected by climate change. For instance, in the A2 model, the number of children severely stunted in SSA by 2050 is likely to increase by $31-55 \%$ (Niang, et al. 2014). The threat of food insecurity in Africa will be exacerbated by factors already present, such as poverty, high population growth rates and environmental degradation. Malnutrition will also impact and be impacted by the spread of vector-borne diseases into previously unoccupied areas due to climate change. In general, there is high confidence that climate change will have a strong negative effect on human nutrition in three ways: fewer calories will be available per person, childhood malnutrition and stunting will increase, and more children will die from undernutrition, with disability-adjusted life years (DALYs) in developing countries increasing as a result (Smith, et al. 2014). One policy implication is that the reinforcing characteristics of malnutrition and disease risk will force decision makers to consider implementing horizontally integrated programs that deal with hunger and other sources of DALYs simultaneously.

There are numerous gaps in the literature about climate change and food security in SSA. Schmidhuber and Tubiello (2007) point out that most studies on food security only examine the aspect of availability of food. More research should be done on how utilization, access and stability will be affected. As well, only the mean change in climate is typically studied. The impact of extreme events and abrupt climatic shifts are usually excluded from analysis (Schmidhuber and Tubiello 2007, Challinor, et al. 2007). Furthermore, the effect of climate change on crop production has typically focused on the world's most common crops, which excludes many crops of key importance in SSA, such as sorghum, millets, yam and banana (Challinor, et al. 2007). Models of food security for Africa in the century ahead will be more accurate if better representations of African crops are included. Lastly, research efforts to develop hardier cultivars of common crops should be expanded (Butt, McCarl and Kergna 2006). 


\section{Review of Policy Literature}

A systematic review of policy literature was undertaken focusing on policies and practices of key UN bodies (e.g. the United Nations Framework Convention on Climate Change and the World Food Programme), international non-profit organizations (e.g. the Bill and Melinda Gates Foundation) and national governments (e.g. Uganda, Kenya, Nigeria, Niger, Mali and Malawi). Despite extensive evidence of the potential impact of climate change on food security in SSA, international organizations have failed to adopt comprehensive policies to adapt to climate change. Plans are typically implemented in only one or a few countries and horizontal integration of climate change policies with other development priorities has been weak. On the local level, some grassroots adaptations have been implemented that show promise, but without stronger institutional support from central governments these practices will likely fail to achieve durable change.

Two of the primary tools available to promote adaptation to climate change in SSA are the Adaptation Fund (AF) and the Green Climate Fund (GCF). The AF was created in 2001 by the UN Framework Convention on Climate Change (UNFCCC) to provide financing to developing countries coping with the effects of climate change (UNFCCC 2014). To date, the AF has provided US\$331 million to 54 countries throughout the world dealing with the effects of climate change. The World Food Programme collaborates with the AF to implement projects in food insecure countries (WFP 2015). Nevertheless, few African countries have received funding due to great global demand on the AF for support. As well, funds are earmarked for a variety of climate change related purposes, from coastal zone management to disaster risk reduction, with food security being only one of many goals.

The GCF was created by the UNFCCC to promote climate adaptation and mitigation in developing nations (UNFCCC 2014). The GCF is the flagship entity behind the UNFCCC goal to raise $\$ 100$ billion per year in climate financing by 2020 . The fund has five main climate change priority areas including development of climate-resilient agriculture. As of May 21, 2015, the GCF has received 50\% of funds pledged to it and its first project approvals were given in November 2015 (Green Climate Fund 2015). However, only three of these projects were in Africa and none of them related to food security. Although research suggests food security will be deeply impacted by climate change, the AF and GCF do not give priority to policies that will combat the threat. More projects to improve food security in SSA should be developed and emphasis should be given to developing institutional capacity within African governments to respond to climate change (Challinor, et al. 2007, Thornton, et al. 2011, Kotir 2011).

The WFP has been more progressive toward designing effective programs to adapt to climate change and build food security in SSA. Most programs developed by the WFP have a country-specific focus, such as the R4 Rural Resilience Initiative that provides climate risk management in Senegal, Ethiopia, Malawi and Zambia (WFP 2015). The WFP also works with the government of Ethiopia to provide an early warning system for droughts and floods. Although the WFP is committed to the dual issues of climate change and food security, most of its projects that integrate the two are limited in scope. They typically involve only one or a few countries in SSA and adaptation activities are rarely integrated with other development plans. Research suggests that a stronger approach would be to mainstream climate change preparedness into all food security plans for SSA (Dinku, et al. 2011).

Nevertheless, the WFP has successfully aligned some programs with gaps identified in the food security literature. The WFP's Climate Services Action for Africa project provides smallholder farmers and pastoralists with weather and climate information via radio, local facilitators and cell phones to enable better livestock and crop decision-making (WFP 2015). Indeed, inadequate communication of weather 
and climate risks to farmers by climate scientists has been identified as a weakness in SSA (Schmidhuber and Tubiello 2007, Dinku et al. 2011). Policies to improve communication practices are worth pursuing because they will enable improved decision making by farmers no matter the climate conditions encountered. The Gates Foundation also supports programs that will enable smallholder farmers to receive weather information by cell phone and radio (2009).

The Gates Foundation has committed $\$ 2$ billion to developing agriculture primarily in SSA and South Asia (Bill and Melinda Gates Foundation 2009).The Foundation recognizes the threat posed by climate change and underscores the importance of sustainable agricultural development. It recently provided \$33 million in funding to the Drought Tolerant Maize for Africa project to aid in the development of drought resistant cultivars (Bill and Melinda Gates Foundation 2015). This project aligns well with development and research priorities noted in the research gaps described previously (Butt, McCarl and Kergna 2006).

Looking at national plans to face climate change, in 2006 the government of Niger developed a plan to address food security and other objectives through 14 adaptation strategies (Nkonya, et al. 2011). These strategies include livestock breeding, pasture and rangeland improvements, rural development, climate information sharing, sustainable activities and water management. Nevertheless, the money to implement these programs is limited and planning remains short-term. In Niger, Nigeria, Uganda, and Kenya major drivers of farmer responses to climate change include level of education, household capital and access to rural services (Nkonya, et al. 2011). Farmers who fail to respond to changes in weather patterns usually say they lacked the money to do so (Nkonya, et al. 2011). If greater emphasis and monetary backing are given to adapting to climate change, farmers will be encouraged to respond to the threat, which will have positive implications for food security. International organizations and national governments alike may reap dividends by embedding climate change in other development priorities and by pursuing no-regret options, which build resilience and generate co-benefits exceeding the costs of implementation. No-regret options have the potential to reduce the burden of disease, build equity and decrease poverty while also adapting to climate change (Watts, et al. 2015).

Farmers can use sustainable land and water management to mitigate or offset some of the impacts of climate change (Nkonya, et al. 2011). Policies to promote these practices can be considered as no-regret options because sustainable practices will improve community resilience regardless of the actual effects of climate change. Some communities in West Africa have begun adapting to climate change through changing planting dates, intercropping and mulching. However, adoption of sustainable techniques in SSA has been limited overall. Thornton et al. (2011) state that the growth of sustainable farming systems can be accelerated by building on knowledge already present in local communities. Governments within SSA should work with local farmers to share knowledge of practices that will assist farmers in adapting to climate change and should work together to stimulate the growth of policies for sustainable agriculture.

Another problem facing governments' ability to anticipate climate change effects results from differences in timescales. Climate models provide insights over decades whereas government planning rarely looks deeper than a few years. In Malawi, government decision making only incorporates 5-10 day weather forecasts and seasonal forecasts (Vincent, et al. 2015). Climate projections over 20 or more years fall beyond the scope of 1-5 year planning cycles. Short- and medium-term planning could be improved by developing national climate models with clear relevance for policymakers. New models must be coupled with enhanced communication and capacity-building at the national level to incorporate climate information into planning. 
In general, sustainable development will be nurtured by embedding climate models into all developent planning (Dinku, et al. 2011). In SSA, National Meteorological and Hydrological Services (NMHSs) as well as regional and sub-regional organizations provide climate forecasts. Yet, government investments in NMHSs remain limited. Usually, NMHSs focus on weather rather than climate, and the needs of international organizations rather than local communities. Climate atlases and crop calendars that provide information to farmers are outdated and not representive of current climates. Information from NMHSs is not being utilized by national planners, and the knowledge NMHSs provide is rarely tailored toward end users (Dinku, et al. 2011). Collaboration between the climate community, policymakers and local communities must be fostered through increased dialogue that emphasizes relevant information. Knowledge generated by climate scientists should be used to inform all aspects of policymaking.

To sum up, the two strongest recommendations for how research literature is able to inform policy are to pursue no-regret options and mainstream climate adaptation into development priorities. These two recommendations will reduce the cost of adaptations and improve horizontal integration of adaptation plans. National governments and international organizations alike have a role to play in adapting to climate change.

However, international organizations may be required to make the first move in emphasizing climate adaptation and building knowledge of climate change in Africa before the problem gains traction among national governments. Evidence suggests that climate change is rarely seen as a pressing issue in SSA and governments often lack knowledge of the problem (Dinku, et al. 2011). Climate change may appear as unimportant relative to clear problems in health, economy and education. Ultimately, action will be required at multiple levels, across nations, within nations and within local communities, in order to reduce the risks to food security that climate change poses.

\section{Conclusion}

Climate change is predicted to have severe negative impacts on food security in Africa. The four dimensions of food security identified by the FAO- availability, access, stability and utilization -will each face new challenges in the coming decades. Availability of food in particular will be damaged due to predicted losses in agricultural yields, which may in turn reduce food access (through reduced trade) and stability (through reduced potential to create food stockpiles). The adaptation mechanisms presently available to deal with a drastically warming climate may be inadequate unless climate change mitigation is simultaneously pursued.

Policies to combat climate change and improve food security in Africa are beginning to be developed but remain fragmented and incomplete. There is evidence that the root causes of poverty and vulnerability will need to be addressed for people to be able to cope with climate change (UN 2013). Development efforts must combine social and environmental issues in order to effectively address climate change. Possibilities exist to incorporate equity goals into policy planning by including the poor, women, and vulnerable groups in system-oriented approaches (Niang, et al. 2014).

Nevertheless, adaptation has its limits. The IPCC foresees very high risks for African food security if global temperatures increase by $4^{\circ} \mathrm{C}$ or more with limited potential for adaptation. This will hold catastrophic consequences for health in Africa. Global priorities must be to mitigate climate change as much as possible while pursuing no-regret options in sub-Saharan Africa. Using current models, most SRES scenarios predict that by 2080 , SSA will have $40-50 \%$ of the world's hungry (Schmidhuber and Tubiello 2007). National governments and international organizations must take steps to fortify agriculture to the effects of climate 
change. If no action is taken, famines will multiply, populations will be displaced and the impacts of food insecurity in Africa could ripple throughout the world. 


\section{References}

Bill and Melinda Gates Foundation. "Bill Gates Calls for Support of World's Poorest Farmers." gatesfoundation.org. 2009. Accessed November 23, 2015.

http://www.gatesfoundation.org/Media-Center/Press-Releases/2009/10/Bill-Gates-Calls-forUnited-Action-to-Support-Worlds-Poorest-Farmers

Bill and Melinda Gates Foundation. "Climate-ready Maize Gets a Boost: Phase III of the Drought Tolerant Maize in Africa Project to Reach More Farmers." gatesfoundation.org. 2015. Accessed November 23, 2015. http://www.gatesfoundation.org/Media-Center/PressReleases/2012/02/Phase-III-of-the-Drought-Tolerant-Maize-in-Africa-Project.

Butt, Tanveer A., Bruce A. McCarl, and Alpha O. Kergna. "Policies for reducing agricultural sector vulnerability to climate change in Mali." Climate Policy 5, (2006): 583-598.

Challinor, Andrew, Tim Wheeler, Chris Garforth, Peter Craufurd, and Amir Kassam. "Assessing the vulnerability of food crop systems in Africa to climate change." Climatic Change 83, (2007): 381389.

Dinku, T., et al. Climate science, information, and services in Arica: Status, gaps, and policy implications. Working Paper, Addis Ababa: African Climate Policy Centre (ACPC) of the United Nations Economic Commission for Africa (UNECA) under the Climate for Development in Africa Program, 2011.

FAO. Regional overview of food insecurity: African food insecurity prospects brighter than ever. Accra: FAO, 2015.

Green Climate Fund. "Green Climate Fund Approves First 8 Investments." Green Climate. November 6, 2015. Accessed November 27, 2015. http://www.greenclimate.fund/documents/20182/38417/Green_ Climate_Fund_approves_first_8_investments.pdf/679227c6-c037-4b50-9636-fec1cd7e8588

IPCC. Climate Change 2014: Synthesis Report Summary for Policymakers. Geneva: Intergovernmental Panel on Climate Change, 2014.

Kotir, Julius H. "Climate change and variability in sub-Saharan Africa: A review of current and future trends and impacts on agriculture and food security." Environment, Development, and Sustainability 13, (2011): 587-605.

Niang, I., et al. "Chapter 22: Africa." In Climate Change 2014: Impacts, Adaptation, and Vulnerability. Part B: Regional Aspects Contribtion of Working Group II to the Flfth Assessment Report of the Intergovernmental Panel on Climate Change, by V.R. Barros, et al., 1199-1265. Cambridge: Cambridge University Press, 2014.

Nkonya, Ephraim, et al. Climate risk management through sustainable land management in sub-Saharan Africa. Discussion Paper, International Food Policy Research Institute, 2011.

Porter, J.R., et al. "Chapter 7: Food security and food production systems." In Climate Change 2014: Impacts, Adaptation, and Vulnerability Part A: Global and Sectoral Aspects. Contribution of 
Working Group II to the Fifth Assessment Report of the Intergovernmental Panel on Climate Change, by V.R. Barros, et al., 485-533. Cambridge: Cambridge University Press, 2014.

Schmidhuber, Josef, and Francesco N. Tubiello. "Global food security under climate change." Proceedings of the National Academy of Sciences, (2007): 19703-19708.

Smith, K.R., et al. "Chapter 11: Human health: impacts, adaptation, and co-benefits." In Climate Change 2014: Impacts, Adaptation, and Vulnerability. Part A: Global and Sectoral Aspects. Contribution of Working Group II to the Fifth Assessment Report of the Intergovernmental Panel on Climate Change, by V.R. Barros, et al., 709-754. Cambridge: Cambridge University Press, 2014.

St. Louis, Michael E., and Jeremy J. Hess. "Climate change: Impacts and implications for global health." American Journal of Preventative Medicine 35, no. 5, (2008): 527-538.

Thornton, Philip K., Peter G. Jones, Polly J. Ericksen, and Andrew J. Challinor. "Agriculture and food systems in sub-Saharan Africa in a $4{ }^{\circ} \mathrm{C}+$ world." Philosophical Transactions of the Royal Society 369, (2011): 117-136.

UN. A new global partnership: Eradicate poverty and transform economies through sustainable development. Report of the High-Level Panel of eminent persons on the post 2015 development agenda, New York: United Nations, 2013.

UNFCCC. Adaptation Fund. 2014. Accessed November 25, 2015. http://unfccc.int/cooperation_and_support/financial_ mechanism/adaptation_fund/items/3659.php

UNFCCC. Green Climate Fund. 2014. Accessed November 25, 2015. http://unfccc.int/cooperation_and_support/financial_ mechanism/green_climate_fund/items/5869.php

Vincent, Katharine, Andrew J. Dougill, Jami L. Dixon, Lindsay C. Stringer, and Tracy Cull. "Identifying climate services needs for national planning: insights from Malawi." Climate Policy, (2015): 1-15.

Wang, Helena, and Richard Horton. "Tackling climate change: the greatest opportunity for global health." The Lancet, (2015): 1798-1799.

Watts, Nick, et al. "Health and climate change: policy responses to protect public health." The Lancet, (2015): 1-53.

WFP. How Climate Change Affects Hunger. 2015. Accessed November 23, 2015. http://www.wfp.org/climate-change

WHO. Food Security. 2015. Accessed November 16, 2015. http://www.who.int/trade/glossary/story028/en/ 